\title{
Yaratıcı Okuma Çalışmalarının Yaratıcı Düşünme Becerilerini Geliştirmeye Etkisi *
}

\author{
The Effects of Creative Reading Practices on the Skills of Creative \\ Thinking \\ İbrahim Halil YURDAKAL** \\ • Geliş Tarihi: 06.12.2018 • Kabul Tarihi: 19.03.2019 • Yayın Tarihi: 28.06.2019
}

\begin{abstract}
$\ddot{O} \mathbf{z}$
Her çağın kendine özgü toplumsal yaşamı belirleyici olguları vardır. Günümüz bilgi çağında bu olgu "bilgi üretme" olarak karşımıza çıkmaktadır. Çağımızda başarının sırrı yeni, uygulanabilir ve işe yarar bilgiler üretmektir. Bu bağlamda günümüzde yetiştirilmesi planlanan insan profilinin bu üç özelliğe sahip olması gerekmektedir. Yeni ve faydalı bilgi üretmenin ilk koşulu yaratıcılık olduğundan bilgi edinmede önemli bir yer kaplayan okumanın da yaratıcı temelli yapılandırılması gerekmektedir. Bu çalışmada yaratıcı okumanın yaratıcı düşünmeye etkisi belirlenmeye çalışılmıştır. Ön test-son test kontrol gruplu yarı deneysel desene göre desenlenen çalışmanın örneklemini 2017-2018 eğitim-öğretim yılında Denizli Pamukkale ilçesi MEB'e bağl1 bir ilkokulda öğrenim gören iki dördüncü sınıf oluşturmaktadır. Deney ve kontrol grupları 19'ar öğrenciden oluşmaktadır. Araştırmada veri toplamada Whetton ve Cameron'un (2002) geliştirmiş olduğu "How creative are you?" adlı ölçeğin Aksoy (2004) tarafından Türkçeye uyarlanmış versiyonu olan "Ne Kadar Yaratıcısınız" ölçeği kullanılmıştır. 14 hafta süren uygulamada deney grubuna yaratıcı okuma süreci ve yaratıcı okuma teknikleri uygulanırken, kontrol grubuna 2015 Türkçe öğretim programı uygulanmıştır. Araştırmadan elde edilen sonuçlar. Türkçe öğretim programı ile yapılan okuma çalışmaları öğrencilerin yaratıcı düşünme becerilerini anlamlı düzeyde azalttığı, yaratıcı okuma ile yapılan okuma çalışmalarının ise öğrencilerin yaratıcı düşünme becerilerini anlamlı bir şekilde artırdığı yönündedir. Ayrıca deney ve kontrol gruplarının son testlerine bakıldığında yaratıcı okuma yapılan deney grubunun yaratıcı düşünme becerileri kontrol grubuna göre anlamlı düzeyde yüksektir.
\end{abstract}

Anahtar sözcükler: yaratıcılık, yaratıcı düşünme, okuma, yaratıcı okuma.

Atıf:

Yurdakal, H.İ. (2019). Yaratıcı okuma çalışmalarının yaratıcı düşünme becerilerini geliştirmeye etkisi.

Pamukkale Üniversitesi Eğitim Fakültesi Dergisi,47, 130-144. doi: 10.9779/pauefd.492812

\footnotetext{
* Bu araştırma yazarın "Yaratıcı okuma çalışmalarının ilkokul 4. sınıfta okuma ve yaratıcı düşünme becerilerini geliştirmeye etkisi" başlıklı doktora tezinden uyarlanmıştır.

*** Dr., Pamukkale Üniversitesi Eğitim Fakültesi, Denizli. ORCİD: 0000-0002-6333-5911, iyurdakal@pau.edu.tr,
} 


\begin{abstract}
Every age has its own unique phenomena forming its social life. In today's information age, this phenomenon is expressed as "producing knowledge". The secret of success in the age of information is to produce new, practical and useful information. In this regard, the human profile that is planned to be trained in the age of information is also required to have these three characteristics. As creativity is the first condition of producing new and beneficial information, reading which has an important place in acquiring information needs to be based on creativity. In this study, it was tried to determine the effect of creative reading on creative thinking. The present study employs an experimental research methodology using pre-test and post-test control group design. The sampling of the study is composed of two classes of fourth grade students attending a school affiliated to the Ministry of National Education (MoNE). Experimental and control groups consist of 19 students. As the data collection tools, "How creative are you?" scale was used which developed by Whetton and Cameron (2002) and adapted to Turkish by Aksoy (2004). In the 14 weeks of application, the experimental group was applied creative reading process and creative reading techniques, control group was applied 2015 Turkish curriculum. The findings can be summarized as follows: Reading studies conducted with the Turkish teaching program resulted in a significant decrease in the students 'ability to think creatively and reading studies with creative reading significantly increased the students' creative thinking skills. Furthermore, when examined final tests of experimental and control groups, the creative thinking skills of the experimental group with creative reading are significantly higher than the control group.
\end{abstract}

Keywords: creativity, creative thinking, reading, creative reading.

\title{
Cited:
}

Yurdakal, H.İ. (2019). The effects of creative reading practices on the skills of creative thinking. Pamukkale Üniversitesi Eğitim Fakültesi Dergisi, 47, 130-144.doi: 10.9779/pauefd.492812 


\section{Giriş}

Ülkelerin eğitim sistemleri yönetim erkleri tarafindan tasarlanan kanun metinleri üzerine kurgulanmıştır. Bu kapsamda ülkelerin eğitime ilişkin kanunlarını incelemek o ülkenin eğitim vizyonunu ve eğitsel hedeflerini görmek açısından yararlı olacaktır. Özellikle kanunlarda yer alan eğitsel hedefler ile o ülkenin yetiştirmek istediği ideal vatandaşın sahip olması gereken özellikleri tespit edilebilir. 1739 Sayılı Millî Eğitim Temel Kanunu'na göre Türk Millî Eğitiminin genel amaçları madde 2'de "beden, zihin, ahlâk, ruh ve duygu bakımlarından dengeli ve sağlıklı şekilde gelişmiş bir kişiliğe ve karaktere, hür ve bilimsel düşünme gücüne, geniş bir dünya görüşüne sahip, insan haklarına saygıl1, kişilik ve teşebbüse değer veren, topluma karş1 sorumluluk duyan; yapıcı, yaratıcı ve verimli kişiler olarak yetiştirmek" (MEB, 2009, s. 7) ifadesi yer almaktadır. Söz konusu maddeye bakıldığında "yaratıcı kişiler yetiştirmek" ifadesi göze çarpmaktadır. Eğitim sisteminin temel amaçlarından birisi yaratıcı bireyler yetiştirmek ise özellikle Türkçe öğretiminin dört temel alanında (dinleme, konuşma, okuma ve yazma) bireylerden yaratıc1lıklarını kullanmaları beklenmektedir. Bu kapsamda yaratıcı düşünme becerisinin Türk Milli Eğitiminin hedefleri arasında olduğu söylenebilir.

Bununla birlikte Türkçe Dersi Öğretim Programı'nda yer alan amaçlarda yaratıcı düşünen bireylerin yetiştirilmesine vurgu yapılmıştır. Türkçe Dersi Öğretim Programı ile basılı ve elektronik ortamlarda dinlediklerini ve okuduklarını anlayan, kendilerini yazılı ve sözlü olarak ifade eden; eleştirel, yansıtıcı ve yaratıcı düşünen, millî, manevi ve evrensel değerlere duyarlı bireyler yetiştirilmesi amaçlanmıştır (MEB, 2015, s. 4). Benzer şekilde genel amaçlarda "bilimsel, yapıcı, eleştirel ve yaratıcı düşünme, kendini ifade etme, iletişim kurma, iş birliği yapma, problem çözme ve girişimcilik gibi temel becerilerini geliştirmek" ifadesi geçmektedir (MEB, 2015, s. 5). 2017 yılında hazırlanan taslak Türkçe Öğretim Programı'nda da buna benzer ifadeler yer almaktadır. Söz konusu programda "öğretim programlarında düşünce biçimini içselleştiren, analitik ve yaratıcı düşünme becerilerinin gelişmesine izin veren bir yolla hayati tecrübeyi zenginleştirmeye, tarihsel birikimi tanımaya ve onu yeniden üretebilmenin yollarına ulaşmaya önem verilmiştir" (MEB, 2017, s. 3). 2018 yılında yayınlanan Türkçe Öğretim Programı ile Avrupa yeterlilikler çerçevesine uygun olarak hazırlanan TYÇ (Türkiye Yeterlilikler Çerçevesi)'nin hedefleri ülkemizdeki tüm yeterliliklerin tanımlandığı, sınıflandırıldığı ve bunun sonucunda yeterlilikler arasında geçiş ve ilerleme gibi ilişkilerin belirlendiği bütünleşik bir yapı sunmak olarak ifade edilmektedir. Bu yeterlilikler çerçevesinde sekiz anahtar yetkinlik programda yer almıştır. Bu yetkinlikler içerisinde özellikle "inisiyatif alma ve girişimcilik" ve "kültürel farkındalık ve ifade" yetkinliklerinde yaratıcılığa ve yaratıcı düşünmeye vurgu yapıldığı görülmektedir.

Yaratıcı düşünme ile yaratıcılık her ne kadar özdeş gibi görülse de bir takım kavramsal farklı1ıklar içermektedir. Bu bağlamda yaratıcı düşünme ve yaratıcılığın aynı anlama gelmemesine rağmen birbiri yerine kullanılabilen iki kavram olarak karşımıza çıktığ söylenebilir. Yaratıcı düşünme daha çok zihinsel etkinlikleri kapsamaktadır. Yaratıcılık ise yaratıcı düşünme sonucu elde edilen düşünce kalıpları ile özgün ürünler ortaya koyma sürecidir. Kısaca yaratıcı düşünme zihinsel bir süreç iken yaratıcılık bu sürecin bir ürün ortaya koyulması ve ürünün pratiğe dökülmesi ile sonuçlanmaktadır. Yaratıcı düşünen insan bütün fikirleri bilmek ister, bunun sebebi ise bütün fikirlerin bilinmesi ile yeni bir fikir ortaya çıkabilmesidir (Von Oech, 1983). Bu kapsamda yaratıcı düşünen insanların merak duygularının gelişmiş olduğu 
söylenebilir. Özellikle özgün olma ve farklı yollar izleme yaratıcı düşünmenin olmazsa olmaz iki özelliğidir. Kalıplaşmış sıradan problem çözümleri ile yetinmeyip mevcut soruna bilinmeyen farklı çözüm önerileri ve çözüm yolları sunmak yaratıcı bireylerin özelliklerindendir. Yaratıcılık kavramında olduğu gibi yaratıcı düşünmede de uzlaşılmış bir tanım bulunmamaktadır. Alan yazına bakıldığında yaratıcı düşünme ile ilgili tanımlamaları şu şekilde sıralayabiliriz; Rawlinson'a (1995) göre yaratıcı düşünme daha önce aralarında ilişki kurulmamış nesne veya durumlar arasında ilişki kurma sürecidir. Yaratıcı düşünme de eleştirel düşünme gibi bireyin hem eğitim hayatında hem de yaşamının diğer alanlarında önemli bir düşünme stilidir. $\mathrm{Bu}$ düşünce stili anlama, tanımlama, veri çözme, yargılama, uygun hale getirme gibi beceriler içermekle birlikte bu süreçte inanışlar önemli yer tutmaktadır (Emanuel ve Challons-Lipton, 2012, s. 1). Yaratıc1 düşünce, eğitim ve meslek alanında başarı için gereklidir. Bu nedenle eğitim yoluyla kazandırılması gereken en üst düzey düşünme becerisi olmalıdır. Yaratıcılık çok boyutlu bir olgu olup her bireyde belli bir düzeyde bulunmaktadır. Bu kapsamda bireylerde yaratıcılık var ya da yok gibi tanımlamalara gitmek büyük bir hatadır.

Yaratıcılık süreci farklı zihinsel ve kişisel özelliklerden oluşan bir yapıdır. Her bir yapı benzer zihinsel süreçlerden oluşmasına rağmen farklı özellikler göstermektedir. Bu yapılar bireyin sahip olduğu olguları farklı kombinasyonlar içinde zihinsel aktivitelere sokarak sıra dış1 ve farklı sonuçlar ortaya koymasını sağlar (Boden 1990, s. 259). Yaratıcılık insanların çevreye uyum sağlaması ve kendini geliştirebilmesi için sahip olması gereken kaçınılmaz bir özelliktir. $\mathrm{Bu}$ sebepten ötürü yıllardır araştırmacılar yaratıcı düşünmenin nasıl oluştuğu ve yaratıcı düşüncenin nasıl geliştiği üzerinde araştırmalar yapmışlardır (Simonton, 2003). Yaratıcı düşünme öğrenilebilmekte ve geliştirilebilmektedir (Yıldırım, 1998). Her bireyin belirli oranlarda -zekâ düzeyi gibi- yaratıcı düşünme yetisi vardır. Ancak zekada olduğu gibi yaratıcı düşünme yeteneği de belirli şartlar sağlandığında geliştirilebilir ya da köreltilebilir. Çevresel ve içsel faktörler etkin bir şekilde harekete geçirildiğinde yaratıcı düşünme becerisinin de artacağı bilinen bir gerçektir. Alan yazına bakıldığında okuma ve yazma becerileri için gereken özellikler ile yaratıcılık için gereken beceriler benzerlik göstermektedir (McVey, 2008; Sak, 2014). Yaratıcı düşünme bireylerin etkin bir şekilde problem çözmelerine katkı sağlar (Mumford ve Gustafson, 1988). Yaratıcı düşüncede, yeni fikirleri üretmenin anlamı geçmişte karşılaşılan sorunlar için üretilen fikirleri baz alarak yeni fikirler üretmek değildir. Yaratıcı düşüncede başarılı olmak için daha önceden var olan varsayımlara ya da üretilmiş olan fikirlere meydan okunması gerekir. Yaratıcı düşünme, problemlere duyarlı olmayı, akıcıllı̆ı, esnekliği, orijinalliği ve yeniden tasvir etme gibi yetenekleri içerir (Torrance ve Goff, 1989, s. 136-137). NACCCE (1999, s. 30) yaratıcı düşünme süreci ile ilgili özellikleri şu şekilde belirtmektedir. Yaratıcı düşünme hayatın her anında ve her boyutunda kullanılmaktadır. Birçok insan yaratıcı olmasına rağmen belirli şartlardan ötürü yaratıcı olduklarının farkında değillerdir. Yaratıcı düşünme iş birliği ve etkileşim sonucu oluşabilir. Bu kapsamda iş hayatında, organizasyonlarda ve benzeri alanlarda, toplumda her an yaratıcı düşünme süreçleri kullanılmaktadır.

Tüm bu gerekçelerden yola çıkarak yaratıcı düşünmenin toplumsal yaşamın bir sonucu olarak yaşamın her anında kullanıldığı, her insanda belirli bir düzeyde yaratıcı düşünme gücünün var olduğu söylenebilir. Yaratıcı düşünme daima özgünlük içermektedir. Bireylerin orijinalliği farklı kategorilere ayrılabilir. Bunlar; Kişisel: Bireyin oluşturduğu ürünler ve eski yaşantısında ürettiği düşünceler orijinal olabilir. İlişkisel: Bireyin orijinalliği iş birliği içindeki çalışmalarda artabilir. Tarihsel: Bir ürün birey için orijinal olabilmektedir. Ancak bir başkası 
için orijinal sayılmayabilir. Bu kapsamda orijinallik bireyin tarihsel perspektifi ile ilişkilidir. Yaratıcı düşünme becerisi pratik uygulamalar ile geliştirilebilmektedir. Bu uygulamalara yaratıcı ürünler geliştirme, müzik, hikâye yazma, deney yapma örnek olarak gösterilebilir. Öğretmenlerin temel görevi de öğrencilerine bu tür uygulamaları yaptırmak olmalıdır. (NACCCE, 1999, s. 34).

Yaratıcı okuma bir öyküyü canlandırırken, müzik dinlerken, dans ederken, görsel sanatlar ile ilgilenirken veya yeni bir karakter ya da temaya bürünürken kullanılan bir okuma çeşididir (Boothby, 1980, s. 675). Yaratıcı okuma okuyucunun daha önceki deneyimlerini ve ilişkisel düşünme süreçlerini kullanarak kendi için yeni bir yorum yaratma süreci olup bu süreç çoğunlukla sorgulama ve yargılamaya dayalıdır (Nardelli ve Nardelli, 1955, s. 6). Yaratıcı okuma sürecinde kişinin geçmiş deneyimleri önem arz etmektedir. Birey eski yaşantılarına ve eski öğrenmelerine bakarak mevcut okuma metnini yapılandırır ve yeni bir metin oluşturur. Yaratıcı okuma çıkarım yapmak, ima etmek, uygun tepkileri vermek ve eleştirel değerlendirme yapmak için yapılan okuma olarak nitelendirilebilir (Adams, 1968).

Yaratıcı düşünmeyi artırdığı düşünülen yaratıcı okumanın ilkokullarda kullanılması durumunda ortaya çıkacak sonuçların belirlenmesi için deneysel çalışmalara ihtiyaç vardır. Bu kapsamda bu araştırmada yaratıcı okumanın yaratıcı düşünme becerisine etkisi incelenmiştir. $\mathrm{Bu}$ amaç kapsamında şu alt problemler belirlenmiştir:

- 2015 Türkçe Dersi Öğretim Programı çerçevesinde okuma çalışmaları yaptırılan 4. sınıf öğrencilerinin yaratıcı düşünme becerileri ön ve son testleri arasında anlamlı bir farklılık var midir?

- Yaratıcı okumaya dayalı olarak okuma çalışmaları yaptırılan 4. sınıf öğrencilerinin yaratıcı düşünme becerileri ön ve son testleri arasında anlamlı bir farklılık var mıdır?

- 2015 Türkçe Öğretim Programı'nın uygulandığı 4. sınıf öğrencileri (kontrol grubu) ile yaratıcı okumaya dayalı okuma çalışmalarının yapıldığı 4. sınıf öğrencilerinin (deney grubu) "yaratıcı düşünme becerileri” son testleri arasında anlamlı bir farklılık var mıdır?

\section{Yöntem}

\section{Araştırma Modeli}

Araştırmanın yöntemi nicel desen üzerinden yapılandırılmıştır. Nicel araştırma süreci var olan teoriler üzerinden deney ve gözlemler yapılmasına dayanmaktadır (Leedy ve Ormrod, 2001). Benzer şekilde Creswell'e (2003, s. 18) göre nicel araştırma yaklaşımı deneysel veya gözlemsel stratejileri kullanarak, istatistiksel sonuçlara ulaşmak için veri toplama süreci olarak tanımlanmaktadır. Araştırmada deneysel modellerden yarı deneysel araştırma modeli kullanılmıştır. Daha önceden oluşturulmuş gruplardan birinin ya da birkaçının kontrol grubu olmasına rastgele karar verildiği araştırmalar yarı deneysel olarak adlandırılmaktadır (Özmen, 2015, s. 60).

\section{Örneklem}

Araştırma kapsamında birbirlerine denk oldukları varsayılan (istatistiki olarak deneysel çalışma öncesi deney ve kontrol gruplarının akademik başarıları denkleştirilse de psiko-sosyal ve fiziksel özellikleri çalışma dışı bırakılmıştır) 2 ayrı 4. sınıf öğrencileri araştırmanın örneklemini oluşturmaktadır. Bu gruplardan birisi deney diğeri ise kontrol grubudur. Denizli Milli Eğitim Müdürlüğü ve Valilik’ten alınan izin doğrultusunda Denizli Pamukkale İlçesinde yer alan bir 
ilkokulda uygulama yapılmışıı. Uygulama kapsamında deney ve kontrol grupları tespit edilmiştir. Uygulama yapılan okuldan rastgele bir sınıf deney bir grup ise kontrol grubu olarak belirlenmiştir. Deney grubu ve kontrol grubu 19 öğrenciden oluşmaktadır. Deney grubu $11 \mathrm{kız}$ ve 8 erkek öğrenciden oluşurken kontrol grubu 10 kız 9 erkek öğrenciden oluşmaktadır. Yapılan ölçümler sonucu deney ve kontrol gruplarının yaratıcı düşünme becerileri ölçeğinin ön testlerinden aldıkları puanların benzer oldukları görülmüştür $(\mathrm{p}=0.19, \mathrm{t} 18=-1,334$ ve $\mathrm{p}>0.05)$.

\section{Veri toplama araçları}

Öğrencilerin yaratıcı düşünme becerilerini belirlemede Whetton ve Cameron'dan (2002) alınan "How creative are you?" adlı ölçeğin, Aksoy (2004) tarafından Türkçeye "Yaratıcı Düşünme Becerisi Ölçeği” adıyla uyarlanan halinden yararlanılmıştır. Yaratıcılık ölçeği öğrencilerin sahip olduğu özellikler, tutumlar, değerler, güdüler ve ilgileri karakterize etmektedir. Ayrıca öğrencilerin yüksek yaratıcı kişiliklerinin belirlenmesine yardımcı olmak amacıyla geliştirilmiştir (Aksoy, 2004, s. 195-196). Ölçekte yer alan, öğrencilerin yaratıcılık özelliklerini belirlemeye yönelik her bir ifade için "Katılıyorum", "Kararsızım", "Katılmıyorum" seçenekleri sunulmuş ve araştırmaya katılan öğrencilerden kendileri için en uygun olan seçeneği işaretlemeleri istenmiştir. Tek faktörden oluşan ölçekte toplam 40 madde yer almakta olup her bir maddenin puanlaması farklı olmuştur. Ölçekte yer alan 39 madde dereceleme ölçeği türünde olup 40. madde ise verilen sıfatları seçme şeklindedir. Ölçeğin geçerlik ve güvenirlik çalışmaları 174 öğrenci üzerinde yapılmıştır. Tek faktörlü ölçeğin açılanan varyans oranı $\% 45$ olup ölçeğe ilişkin Chronbach's Alpha güvenirlik katsayısı ise 0,94'tür.

\section{Veri toplama süreci}

Araştırmada 1 kontrol ve 1 deney grubu olmak üzere iki grup ele alınmıştır. Deney ve kontrol gruplarının öntest ve sontest verileri bizzat araştırmacı tarafından toplanmıştır. Ayrıca kontrol grubundaki öğretmene araştırma hakkında bilgi verilmiştir. Deney grubunu araştırmacı; kontrol grubunu ise sınıf öğretmeni yürütmüştür. Kontrol grubunun öğretmeni ile deney grubunun uygulayıcısı kıdem, eğitim düzeyi ve mezuniyet durumuna göre eşleştirilerek güvenirlik artırılmaya çalışılmıştır. 14 haftalık süreç boyunca deney grubuna yaratıcı okumaya dayalı Türkçe dersi; kontrol gruplarına ise MEB tarafından belirlenen Türkçe dersi uygulanmıştır. Uygulama 2017-2018 eğitim-öğretim yılında yapıldığından dolayı 2015 Türkçe Dersi Öğretim Programı baz alınmıştır. Yaratıcı okumaya dayalı Türkçe öğretimi programının hazırlanmasında Ada (1987) tarafından metodolojisi hazırlanan yaratıcı okuma süreci kullanılmıştır. Alan yazın incelediğinde yaratıcı okuma (creative reading) uygulamalarında kabul görmüş bir süreç olduğu görülmektedir. Bu kapsamda ilkokul 4. sınıf öğrencilerinin seviyelerine uygun bilgilendirici, öyküleyici ve şiir tarzında metinler programa ek olarak seçilerek öğretim yapılmıştır. Ayrıca metne bağlı olarak yaratıcı okumaya özgü teknikler kullanılmıştır. Söz konusu teknikler şunlardır: Tek kelime değişimi, satır atlama, satır değişimi, üstten veya alttan yer değiştirme, kenarları fluleştirme, sayfa atlama, sayfa tekrarı, göz-zihin ayrımı, satır konfüzyonu, satırlar arası akış, kitapların düellosu, şablon çizimi, gün tonlaması, gece tonlaması, sessizlik, yabancı dil, boş sayfa (Yurdakal, 2018). 


\section{Bulgular}

\section{Birinci Alt Probleme İlişkin Bulgular}

“2015 Türkçe Dersi Öğretim Programı ile yapılan okuma çalışmaları 4. sınıf öğrencilerinin yaratıcı düşünme becerilerinin ön ve son testleri arasında anlamlı bir farklılık oluşturmakta mıdır?" alt problemine ilişkin bulgular şunlardır; Tablo 1'de kontrol grubunun ön ve son testlerine ilişkin yaratıcı düşünme becerisi ölçeği sonuçları verilmiştir.

Tablo 1: Kontrol Grubu Yaratıcı Düşünme Ölçeğine İlişkin Ön ve Son Test İlişkili Örneklem T Testi Analiz Sonuçları

\begin{tabular}{lccccccc}
\hline \multicolumn{1}{c}{ Ölçüm } & N & $\overline{\mathbf{x}}$ & ss & sd & t & $p$ & $\mathrm{~d}$ \\
\hline Kontrol grubu ön test & 19 & 88,63 & 12,49 & 18 & 3,184 & 0.005 & 0.73 \\
\hline Kontrol grubu son test & 19 & 74,21 & 17,32 & & & & \\
\hline
\end{tabular}

Tablo 1'e bakıldığında kontrol grubunun yaratıcı düşünme becerisine ilişkin ön test puan ortalamaları Kön=88,63 iken son test ortalamas1 Kson=74,21'dir. Bu kapsamda kontrol grubunun yaratıcı düşünme becerilerini ölçen ölçek puanları ön testlerde son testlere göre daha yüksektir. Bu kapsamda 2015 Türkçe öğretim programı ile işlenen Türkçe derslerinin öğrencilerin yaratıcı düşünme becerilerini azalttığı söylenebilir. Ancak bu farkın anlamlı olup olmadığını belirlemede ilişkili örneklem t testi sonuçlarına bakılmalıdır. Tablo 1'de kontrol grubunun yaratıcı düşünme ölçeği ön ve son testlerinin anlamlılığına ilişkin ilişkili örneklem t testi sonuçları gösterilmiştir. Tablo 1'e bakıldığında 2015 Türkçe öğretim programına dayalı Türkçe derslerinin ön ve son testlerinin yaratıcı düşünme üzerindeki etkisinin araştırıldığ 19 kişilik bir sınıfta uygulama sonrasında yapılan yaratıcı düşünme becerisi ölçeği puan ortalamaları arasında bir farkın olup olmadığını belirlemek için yapılan ilişkili örneklem $t$ testi sonucunda, kontrol grubu ön test sinav puanları ortalaması Xön $=88.63$ ve kontrol grubu son test sinav puanlarının ortalaması Xson=74.21 arasında anlamlı bir farklılık vardır. T (18) $=3,184, p<0.05$. Bu kapsamda 2015 Türkçe Dersi Öğretim Programı ile yapılan Türkçe dersinin yaratıcı düşünme becerisini azalttığı söylenebilir. \%95 olasılıkla deney ve kontrol gruplarının son testleri arasındaki farkın güven aralığı ise 4,90 ile 23,93 arasındadır. Yapılan ilişkili örneklemler için t testi, karşılaştırılan iki ortalama arasında anlamlı bir fark olup olmadığını ortaya koyarken bu farkın büyüklügü hakkında bilgi vermez. Bu nedenle istatistiksel anlamlılığın yanı sıra etki büyüklüğünün de hesaplanması gerekmektedir (Can, 2014, s. 140). $\mathrm{Bu}$ bağlamda etki kuvveti 0.73 olup orta düzeyde bir anlamlılık olduğu görülmektedir. $\mathrm{Bu}$ kapsamda 2015 Türkçe dersi öğretim programı ile yapılan Türkçe derslerinin öğrencilerin yaratıcı düşünme becerilerini orta güçlükte de olsa anlamlı düzeyde daha azalttığı söylenebilir.

\section{İkinci Alt Probleme İlişsin Bulgular}

Araştırmanın ikinci alt problemi olan "Yaratıcı okumaya dayalı yapılan okuma çalışmaları 4. sınıf öğrencilerinin yaratıcı düşünme becerilerinin ön ve son testleri arasında anlamlı bir farklılık oluşturmakta mıdır?" alt problemine ilişkin bulgular şunlardır; Tablo 2'de deney grubunun ön ve son testlerine ilişkin yaratıcı düşünme becerisi ölçeği sonuçları verilmiştir.

Tablo 2: Deney Grubu Yaratıcı Düşünme Ölçeğine İlişkin Ön ve Son Test İlişkili Örneklem T Testi Analiz Sonuçları

\begin{tabular}{lccccccc}
\hline \multicolumn{1}{c}{ Ölçüm } & $\mathrm{N}$ & $\overline{\mathrm{x}}$ & $\mathrm{ss}$ & $\mathrm{sd}$ & $\mathrm{t}$ & $p$ & $\mathrm{~d}$ \\
\hline Deney Grubu ön test & 19 & 84,00 & 6,24 & 18 & $-4,615$ & 0.00 & 1.05 \\
Deney Grubu son test & 19 & 95,42 & 8,28 & & & & \\
\hline
\end{tabular}


Tablo 2'ye bakıldığında deney grubunun yaratıcı düşünme becerisine ilişkin ön test puan ortalamaları Dön=84,00 iken son test ortalamas1 Dson=95,42'dir. Bu kapsamda deney grubunun yaratıcı düşünme becerilerini ölçen ölçek puanları uygulama sonrası artış göstermiştir. $\mathrm{Bu}$ kapsamda yaratıcı okumaya dayalı işlenen Türkçe derslerinin öğrencilerin yaratıcı düşünme becerilerini artırdığı söylenebilir. Ancak bu farkın anlamlı olup olmadığını belirlemede ilişkili örneklem t testi sonuçlarına bakılması gerekmektedir. Tablo 2'de deney grubunun yaratıc1 düşünme ölçeği ön ve son testlerinin anlamlılığına ilişkin ilişkili örneklem $t$ testi sonuçları gösterilmiştir. Tablo 2'ye bakıldığında yaratıcı okumaya dayalı Türkçe derslerinin ön ve son testlerinin yaratıcı düşünme üzerindeki etkisinin araştırıldığı 19 kişilik bir sınıfta uygulama sonrasında yapılan yaratıcı düşünme becerisi ölçeği puan ortalamaları arasında bir farkın olup olmadığını belirlemek için yapılan ilişkili örneklem $t$ testi sonucunda, deney grubu ön test sınav puanları ortalaması Xön= 84.00 ve deney grubu son test sinav puanlarının ortalamas Xson=95.42 arasinda anlamlı bir farklılık vardır. $\mathrm{T}(18)=-4,615, \mathrm{p}<0.05 . \mathrm{Bu}$ kapsamda yaratıc1 okuma ile yapılan Türkçe dersinin yaratıcı düşünme becerisini artırdığı söylenebilir. \%95 olasılıkla deney ve kontrol gruplarının son testleri arasındaki farkın güven aralığı ise -16,62 ile 6,22 arasındadır. Etki kuvveti 1.05 olup çok yüksek düzeyde bir anlaml1lık olduğu görülmektedir. $\mathrm{Bu}$ kapsamda yaratıcı okumaya dayalı işlenen Türkçe derslerinin yaratıcı düşünme becerisi ölçeği son test puanlarının ön test puanlarından anlamlı düzeyde ve olumlu yönde farklılık içermesi nedeniyle yaratıcı okumanın yaratıcı düşünme becerisine çok yüksek oranda ve anlamlı düzeyde etkisi vardır.

\section{Üçüncü Alt Probleme İlişkin Bulgular}

Araştırmanın üçüncü alt problemi olan "2015 Türkçe Öğretim Programı ve yaratıcı okumaya dayalı yapılan okuma çalışmaları 4. sınıf öğrencilerinin "yaratıcı düşünme becerilerinin" son testleri arasında anlamlı bir farklılık oluşturmakta mıdır?" alt problemine ilişkin bulgular şunlardır; Tablo 3'te kontrol ve deney gruplarının son testlerine ilişkin yaratıcı düşünme becerisi ölçeği sonuçları verilmiştir.

Tablo 3: Kontrol ve Deney Grubu Yaratıcı Düşünme Ölçeğine İlişkin Son Test Bağımsız Gruplar T Testi Analiz Sonuçları

\begin{tabular}{lccccccc}
\hline \multicolumn{1}{c}{ Ölçüm } & $\mathrm{N}$ & $\overline{\mathrm{x}}$ & $\mathrm{ss}$ & $\mathrm{sd}$ & $\mathrm{t}$ & $p$ & $\mathrm{~d}$ \\
\hline Kontrol Grubu son test & 19 & 74,21 & 17,32 & 18 & $-5,282$ & 0.00 & 1.21 \\
Deney Grubu son test & 19 & 95,42 & 8,28 & & & & \\
\hline
\end{tabular}

Tablo 3'e bakıldığında kontrol grubunun yaratıcı düşünme becerisine ilişkin son test puan ortalamaları Kson=74,21 iken deney grubunun son test ortalaması Dson=95,42'dir. Bu kapsamda deney grubunun yaratıcı düşünme becerilerini ölçen ölçek puanları uygulama sonrasında kontrol grubundan daha yüksektir. Bu kapsamda yaratıcı okumaya dayalı işlenen Türkçe derslerinin 2015 Türkçe öğretim programı ile işlenen Türkçe dersine göre öğrencilerin yaratıcı düşünme becerilerini daha fazla artırdığı söylenebilir. Ancak bu farkın anlamlı olup olmadığını belirlemede bağımsız gruplar t testi kullanılmıştır. Tablo 3 'te deney ve kontrol gruplarının yaratıcı düşünme ölçeği son testlerinin anlamlılığına ilişkin bağımsız gruplar t testi sonuçları gösterilmiştir. Tablo 3'e bakıldığında yaratıcı okumaya ve 2015 Türkçe Dersi Öğretim Programı'na dayalı Türkçe derslerinin son testlerinin yaratıcı düşünme üzerindeki etkisinin araştırıldığı 19 kişilik bir sınıfta uygulama sonrasında yapılan yaratıcı düşünme becerisi ölçeği puan ortalamaları arasında bir farkın olup olmadığını belirlemek için yapılan bağımsız gruplar $\mathrm{t}$ testi sonucunda, kontrol grubu son test sinav puanları ortalaması Kson=74.21 ve deney grubu 
son test sinav puanlarının ortalaması Dson=95.42 arasında anlamlı bir farklılık vardır. $\mathrm{T}(18)=-$ $5,282, \mathrm{p}<0.05$. Bu kapsamda yaratıcı okuma ile yapılan Türkçe dersinin yaratıcı düşünme becerisini, Türkçe dersi öğretim programı ile yapılan Türkçe derslerine göre daha fazla artırdığı söylenebilir. \%95 olasılıkla deney ve kontrol gruplarının son testleri arasındaki farkın güven aralığı ise $-29,64729$ ile $-12,77376$ arasındadır. Etki kuvveti 1.21 olup çok yüksek düzeyde bir anlamlılık olduğu görülmektedir. Bu kapsamda deney grubunun yaratıcı düşünme becerisi ölçeği son test puanları ile kontrol grubu son test puanları arasında anlamlı bir farklılık vardır. $\mathrm{Bu}$ farkl11ık deney grubu lehine olup farkl11ık çok yüksek düzeydedir $(\mathrm{d}=1.21)$.

\section{Tartışma ve Sonuç}

Kontrol grubu uygulama öncesi yaratıcı düşünme ölçeği ortalama puanları 88.63 iken uygulama sonrası 74.21 olmuştur. Bu kapsamda anlamlı ve yüksek düzeyde bir düşüş görülmektedir. $\mathrm{Bu}$ kapsamda Türkçe Öğretim Programı'na dayalı Türkçe dersleri öğrencilerin yaratıcı düşünme becerilerini azalttı̆̆ 1 söylenebilir. Yaratıcı düşünce, eğitim ve meslek alanında başarı için gereklidir. Bu nedenle eğitim yoluyla kazandırılması gereken en üst düzey düşünme becerisi olmalıdır. Merak ve özgünlük kavramlarını içeren yaratıcılık sayesinde birey, problemlere yeni çözüm yolları bulacak ve sentez yapma becerilerine sahip olacaktır (Yazıcı ve Topalak, 2013, s. 196). Eğitim-öğretim faaliyetlerinin bir takım temel huşuları vardır. Bu hususlar verilen eğitimöğretim faaliyetlerinin amaçlarını ve beklentilerini oluşturur. 2015 Türkçe Öğretim Program'ında “eleştirel düşünme yeni fikirlerin ortaya çıkmasını sağlar. Ayrıca birey, düşüncelerini argümanlar ortaya koyarak savunduğu için bu savunma, düşüncelerin tekrar değerlendirilmesine de olanak tanır. Öğretim programlarında bu düşünce biçimini içselleştiren, analitik ve yaratıcı düşünme becerilerinin gelişmesine izin veren bir yolla hayati tecrübeyi zenginleştirmeye, tarihsel birikimi tanımaya ve onu yeniden üretebilmenin yollarına ulaşmaya önem verilmiştir.” ifadesi yer almaktadır. Kısaca MEB programı yaratıcı düşünmenin gelişmesinin önemini vurgulamış ve programın buna hitap ettiğini belirtmektedir. Ancak gerek okutulan metinlerdeki metin sonu soruları gerekse metinlerin içerikleri yaratıcı düşünceyi geliştirme konusunda kısır kalmaktadır. Kontrol grubunun yaratıcı düşünme becerileri yükselmediği gibi anlamlı düzeyde bir düşüş göstermiştir. Yaratıcı düşünmenin gelişmesi için bilgi edinme süreçlerinin yani okuma-yazma gibi becerilerinde yaratıcı düşünmeye zevk edecek şekilde uygulanması gerekmektedir. Bu kapsamda alıcı okuma yerine yaratıcı okumaya dayalı olarak Türkçe dersleri işlenmelidir. 2015 programında yer almasa da 2018 Türkçe Öğretim Programı'nda Avrupa Yeterlilikler Çerçevesi (AYÇ) ile uyumlu olacak şekilde Türkiye Yeterlilikler Çerçevesi (TYÇ) oluşturulmuştur. Özellikle PISA sınavından alınan olumsuz sonuçlar nedeniyle ülkedeki tüm yeterliliklerin tanımlandığı, sınıflandırıldığı ve bunun sonucunda yeterlilikler arasında geçiş ve ilerleme gibi ilişkilerin belirlendiği bütünleşik bir yap1 sunma amacı taşıyan TYÇ oluşturulmuştur. TYÇ’nin içeriğine bakıldığında yaratıcılık ve yaratıcı düşünme gibi temel unsurların yer aldığı görülmektedir. Bu kapsamda bilgi çağında yaratıcı bireyler yetiştirilmek hedefleniyor ise kılavuz kitapların ve programlarında yaratıcı düşünmeyi geliştirici şekilde hazırlanması gerekmektedir. Programların içeriklerinde yaratıcı düşünme becerisine yer verilmesi yeterli olmamakta uygulamada kullanılan kılavuz kitapların da yaratıcı düşünmeyi geliştirici şekilde hazırlanmaları gerekmektedir.

Yaratıcılık insanların çevreye uyum sağlaması ve kendini geliştirebilmesi için sahip olması gereken kaçınılmaz bir özelliktir. Bu sebepten ötürü yıllardır araştırmacılar yaratıcı 
düşünmenin nasıl oluştuğu ve yaratıcı düşüncenin nasıl geliştiği üzerinde araştırmalar yapmışlardır (Simonton, 2003). Günümüzde bireylerden kendilerini gerçekleştirmeleri ve yaratıcı fikirler üretmeleri beklenmektedir. Bilgi edinme sürecinde önemli bir rol oynayan okuma becerisinin yaratıcı düşünmeyi desteklemesi de beklenmektedir. Bu kapsamda yaratıcı okumanın yaratıcı düşünmeyi olumlu ve yüksek düzeyde etkilemesi istenilen bir durumdur. Nitekim araştırmada yaratıcı okumaya dayalı Türkçe dersleri ile yürütülen deney grubunun yaratıcı düşünme ölçeği ön test puan ortalamaları 84.00 iken son testlerde 95.42 olmuştur. $\mathrm{Bu}$ farklılık anlamlıdır. Ayrıca farklılığın etki kuvveti $(\mathrm{d})=1.05$ olup yüksek düzeyde bir etki ile bu anlamlı1ık ortaya çıkmıştır. Yaratıcı okumada metinle yaşam arasında ilişki kurma, yeni ve orijinal bir ürün ortaya koyma ön plandadır. Nitekim Torrance ve Goff'a, (1989, s. 136-137) göre yaratıcı düşünme, problemlere duyarlı olmayı, akıcılı̆̆ı, esnekliği, orijinalliği ve yeniden tasvir etme gibi yetenekleri içerir. Yaratıcı düşünen bireyler yetiştirmek isteyen bir öğretmen sonuca değil sürece önem verir, problemi çözmek yerine problemi tanımlama ve keşfetmeye önem vermelidir. Kavramların sözlük anlamlarından çok kişisel tanımlarına değer vermelidir. Ezbere dayalı bilgiler yerine öğrencinin gelişimine katkı sağlayacak ve eğitim psikolojisine uygun bilgilere yer vermelidir. Bilinen teoriler/hipotezleri kullanmak yerine iletişim becerilerini güçlendirerek bireyin kendi hipotezlerini kurması sağlanmalıdır. Mevcut düşünceleri kullanarak düşünme yerine yaratıcı ve üretken gücü kullanarak kompleks düşünceyi kullanarak bakış açısı kazandırmalıdır. Gelişigüzel sonuçlara ulaşmak yerine sistematik sonuçlara ulaşmayı hedeflemelidir (Saliceti, 2015, s. 1177). Yaratıc1 okumanın doğas1 gereği ortaya koyulan üründen ziyade ürünün ortaya koyuluşu önem arz etmektedir. Ürün ortaya koyarken kullanılan zihinsel düşünüşler ve orijinal fikirler üründen daha fazla önemsenmektedir. Alıcı okumada çok kullanılan bilinen hipotezler veya bilgiler yerine bireyin kendi bilgilerini, düşüncelerini ve hipotezlerini oluşturmaları beklenir. Birey yaratıcı okuma sürecinde tek yönlü değil kompleks bir bakış açısı ile düşünerek sistematik sonuçlara ulaşır. Bu kapsamda yaratıcı okumanın yaratıcı düşünmeyi olumlu etkilemesi bunlara bağlanabilir.

Araştırma kapsamında 14 haftalık uygulamalar sonucu kontrol grubunda öğrencilerin yaratıcı düşünme becerileri ölçeğinden aldıkları puanlar son testlerde ön testlere göre düşüş yaşamıştır. Yaratıcı okuma yapılan deney grubunda ise öğrencilerin yaratıcı düşünme becerileri anlamlı bir şekilde artış göstermiştir. Nitekim deney ve kontrol gruplarının son testlerine bakıldığında kontrol grubunun yaratıcı düşünme ölçeğinden aldığı son test puan ortalamaları 74.21 iken deney grubunun 95.42'dir. Son testler arasinda anlamlı bir farklılık olup bu anlam deney grubu lehinedir. Yaratıcı okuma hem diğer okuma türlerini kapsamakta hem de diğer okuma türlerinden daha üst basamakta yer almaktadır. Bireyin yaratıcı okuma yapabilmesi için belirli bir okuma olgunluğuna ve okuma becerisine sahip olması gerekmektedir. Yaratıc1 okuma süreci akıcı okumaya göre daha zor bir süreç olarak görülse de uygulamada bunun tersi bir durum söz konusudur. Yaratıcı okumada kullanılan farklı tekniklerin öğrencilerin ilgilerini çekmesi ve yaratıcı okuma sürecinde öğrencilerin hayal güçlerini kullanarak farklı fikirlere ulaşması öğrencilerin merak duygularını geliştirmekte ve dersler daha zevkli ve kolay geçmektedir. $\mathrm{Bu}$ kapsamda bilgi çağında bireylerden beklenilen özelliklerin başında gelen yaratıcı düşünme becerisini artıran yaratıcı okumanın Türkçe derslerinde kullanılması önem arz etmektedir. Belirli bir gösterge yokken ya da alan yazında konu ile ilgili bir bilgi bulunmaz iken okuma materyaline yaratıcı hayal gücünü kullanarak şekil verme sürecine yaratıcı okuma süreci denilmektedir. Günlük hayatın her alanında kullanılan yaratıcı okuma hayatın gizli gerçeklerini 
ve saklı güzelliklerini de bireylere sunmaktadır (Ramsey, 1930, s. 116). Bu bağlamda yaratıcı okuma sürecinin başarılı bir şekilde uygulanabilmesi için bireyin yaratıcı düşünme gücünü ortaya koyması gerekmektedir. Bu gerekçeyle yaratıcı okuma ile yaratıcı düşünme arasında pozitif yönde bir ilişki olması gerekmektedir. Yaratıcı okuma yaratıcı düşünme ve bireyin yaratıcılık gücünü artıracağından çalışma bulguları bu durum ile paralel görülmektedir. 


\section{Kaynakça}

Ada, A. F. (1987). Creative Reading, A Relevant Methodology For Language Minority Children, Theory, Research, and Applications: Selected Papers from the Annual Meetingoi the National Association for Bilingual Education.

Adams, P. J. (1968). Creative Reading, International Reading Assocation, Boston.

Aksoy, B. (2004). Coğrafya öğretiminde probleme dayalı ögrenme yaklaşımı. Yayımlanmamış doktora tezi, Gazi Üniversitesi, Ankara.

Boden, M. A. (1990). The Creative Mind: Myths and Mechanisms. London: Weidenfeld and Nicholson.

Boothby, P. Y. (1980). Creative and critical reading for the gifted, The Reading Teacher, 33 (6), 674-676.

Büyüköztürk, Ş. (2011). Sosyal Bilimler İ̧̧in Veri Analizi El Kitabı - İstatistik, Araştırma Deseni, SPSS Uygulamalart ve Yorum (15. Bask1). Ankara: Pegem Akademi.

Can, A. (2014). SPSS ile Bilimsel Araşttrma Sürecinde Nicel Veri Analizi (3. bs), Ankara: Pegem Akademi.

Creswell, J. (2003). Research Design: Qualitative, Quantitative And Mixed Methods Approaches (2nd ed.). Thousand Oaks, CA: SAGE Publications.

Emanuel, R. C. ve Challons-Lipton, S. (2012). Helping students transition to critical and creative thinking at the intersection of communication and art, International Journal of Humanities and Social Science, 2 (11), 1-9.

Karataş, S. ve Özcan, S. (2010). Yaratıcı düşünme etkinliklerinin öğrencilerin yaratıcı düşünmelerine ve proje geliştirmelerine etkisi. Ahi Evran Üniversitesi Ĕ̆itim Fakültesi Dergisi, 11, 225-243.

Leedy, P. ve Ormrod, J. (2001). Practical research: Planning and design (7th ed.). Upper Saddle River, NJ: Merrill Prentice Hall. Thousand Oaks: SAGE Publications.

McVey, D. (2008). Why all writing is creative writing. Innovations in Education \& Teaching International, 45 (3), 289-294.

MEB (2009). İlköğretim Türkçe Dersi Öğretim Programı ve Kılavuzu (1- 5. Sinıflar), Ankara: Devlet Kitapları Müdürlüğü Basım Evi.

MEB (2015). İlköğretim Türkçe Dersi (1, 2, 3, 4, 5, 6, 7 ve 8. sinıflar) Öğretim Programı. Ankara: Devlet Kitapları Müdürlüğü Basım Evi.

MEB (2017). Taslak Türkçe Dersi Öğretim Programı (İlkokul ve Ortaokul 1, 2, 3, 4, 5, 6, 7 ve 8. Siniflar), Ankara.

Mumford, M. D. ve Gustafson, S. B. (1988) Creativity syndrome: Integration, application and innovation. Psychological Bulletin, 103: 27-43.

NACCCE (1999). National Advisory Committee on Creative and Cultural Education, Report to the Secretary of State for Education and Employment the Secretary of State for Culture, Media and Sport.

Nardelli, R. R. ve Nardelli, R. N. (1955). Creative reading includes emotional factors, The Reading Teacher, 9 (1), 5-10.

Özmen, H. (2015). Deneysel Araştırma Yöntemi, Kuramdan Uygulamaya Eğitimde Bilimsel Araştırma Yöntemleri içinde (Edi: M. Metin), Ankara: Pegem Akademi.

Rawlinson, J. G. (1995). Yaratıcı Düşünme ve Beyin Fırtınası (Creative Thinking And Brain Storming). (Çev: Değirmen, O.). İstanbul: Rota Yayınc1lık.

Ramsey, E. (1930). Creative reading, The Elementary English Review, 7 (5), 116-123.

Saliceti, F. (2015). Educate for creativity, Procedia- Social and Behavioral Sciences, 197: 1174 - 1178.

Simonton, D. K. (2003). Scientific creativity as constrained stochastic behavior: The integration of product, person and process perspectives, Psychological Bulletin, 129, 475-494.

Torrance, E. P. ve Goff, K. (1989). A quiet revolution, Journal of Creative Behavior, 23 (2), 136-145.

Von Oech, R. (1983). Whack on the Side of the Head: How to Unlock Your Mind for Innovation, ABD: Warner Books. 
Yazıcı, T. ve Topalak, Ş. İ. (2013). Yaratıcı düşünme becerisinin müzik öğretiminde kullanılabilirliği ile ilgili öğretmen görüşleri, Eğitim ve Öğretim Araştırmaları Dergisi, 2 (4), 195-204.

Yıldırım, R, (1998), Yaratıcılık ve Yenilik, İstanbul: Sistem Yayıncılık.

Yurdakal, İ. H. (2018). Yaratıcı Okuma, Dil ve Edebiyat Araştırmaları içinde (Edi: G. Alpar), Turkey: Iksad Publication. 


\section{Introduction}

\section{Extended Abstract}

It is expected from the individuals in knowledge-producing societies not just to comprehend the text by reading but also to interpret the text by using metacognitive skills. In this context, creative reading practices have a special importance. While the students are expected to read the text as it is in educational activities conducted through behavioral approach, the readers are expected to read, analyze and synthesize the information obtained from the text in a critical way in cognitive approaches. In the constructivist approach, individuals are expected to interact with information in the text and produce new information. In this context, creative reading is a kind of reading which conforms to the constructivist approach. The importance of creative reading has enhanced as it includes creative thought and authenticity issues. In this context, it is expected that the creative reading, which is thought to reveal the creativity skills expected from individuals in the information age, is used in teaching reading skills to individuals. Especially in primary school age, which is a critical period for cognitive development, creative reading activities will develop students' creativity and creative thinking skills.

\section{Method}

The sample of the study, which was designed according to the pretest-posttest quasiexperimental design, consists of fourth grade students attending a primary school in the Pamukkale district of Denizli in the 2017-2018 academic year. The experimental and control groups consisted of 19 students. To determine the creative thinking skills of the students, "How creative are you?" scale developed by Whetton and Cameron (2002) and adapted to Turkish by Aksoy (2004) was used. Each item on the scale determines the creativity characteristics of the students. Three options were presented as agree, disagree and neutral in the scale, and students were asked to mark the most appropriate option for them. The scale consists of one factor and 40 items, and each item has a different scoring. The validity and reliability studies of the scale were performed on 174 students. The one-factor scale explained the variance ratio of $45 \%$ and Chronbach's Alpha reliability coefficient of the scale is 0.94 .

\section{Findings and Discussion}

The results of the 14-week treatment can be summarized as follows: The creative thinking skills of the students improved in Turkish lessons structured through creative reading (experimental group), while the creative thinking scores of the control group decreased significantly. In the 2015 Turkish Course Curriculum, it is stated that "Critical thinking enables to emerge new ideas. Also, because the individual defends his thoughts by putting up arguments, this defense also allows a rethinking of thoughts. Emphasis has been placed on enriching vital experience, recognizing historical knowledge and reaching ways to reproduce it in a way that embodies this form of thinking and allows for the development of analytical and creative thinking skills in curricula". The curriculum emphasizes the importance of developing creative thinking. However, when we look at the teaching facilities, it is seen that the end of text questions and the content of the texts in the guide books prevent the development of creative thinking. The findings of the research show that there is a significant decrease in the creative thinking skills scores of the control group. In order to develop creative thinking, individuals need to enjoy the text and activities that they read and be interested in the texts. In this context, the decline in the scores of creative thinking skills in the control group can be attributed to this situation. 
In this context, Turkish lessons should be based on creative reading rather than on receptive reading. Turkey Qualifications Framework (TQF) to be compatible with European Qualifications Framework (EQF) has been established in 2018 even if it does not take place in 2015 curriculum. Particularly due to the low results from the PISA exam, the TQF was created with the aim of presenting an integrated structure in which all qualifications in the country are defined, classified, and as a result of which relations such as transition and progress are defined among the competencies. Looking at the content of TQF, it is seen that basic elements such as creativity and creative thinking are involved. In this context, if the aim is to educate creative individuals in the age of information, it is necessary to prepare guide books and programs to develop creative thinking skills. It is not enough to include creative thinking skills in the contents of the curriculum, and the guide books used in practice should be prepared in a way that promotes creative thinking.

Creative reading covers both other types of reading and is at a higher place than other types of reading. In order to be able to read creatively, individuals need to have a certain level of reading maturity and skills. Although the creative reading process is seen as a more difficult process than fluent reading, in practice it is the opposite. Students develop their feelings of curiosity and the lessons are easier and more enjoyable as different techniques used in creative reading attract students' interest and the students reach different ideas by using their imagination in the process of creative reading. In this context, it is crucial to use creative reading in Turkish lessons which increases the creative thinking skills as one of the features expected from the individuals in the information age. 